This is the accepted version of the article:

Troyano J., Carné-Sánchez A., Avci C., I maz I., Maspoch D.. Colloidal metal-organic framework particles: The pioneering case of ZIF-8. Chemical Society Reviews, (2019). 48. : 5534 . 10.1039/c9cs00472f.

Available at: https://dx.doi.org/10.1039/c9cs00472f 


\title{
Colloidal Metal-Organic Framework Particles: the Pioneering Case of ZIF-8
}

Received 00th January 20xx Accepted 00th January 20xx

DOI: $10.1039 / \times 0 \times x 00000 x$

\author{
Javier Troyano, ${ }^{\mathrm{a}}$ Arnau Carné-Sánchez, ${ }^{\mathrm{a}}$ Civan Avci, ${ }^{\mathrm{a}}$ Inhar Imaz ${ }^{\mathrm{a}}$ and Daniel Maspoch*a,b
}

The production of metal-organic frameworks (MOFs) in the form of colloids have brought a paradigm shift in the design of new functional porous materials. Along with their intrinsic interest as porous solids, and contrary to their bulk powdel counterparts, colloidal MOF particles can additionally be dispersed, shaped, functionalized, transformed and assembled in a controlled manner, conferring them further properties and applications. In this regard, zeolitic imidazolate framework-8 (ZIF-8) has become a pioneering MOF constituent of colloidal science. Today, the understanding of the role of synthetic parameters, learned after one decade of research, enables the production of monodisperse colloidal ZIF-8 particles with tunable dimensions and morphologies, offering the opportunity to develop new functional materials and composites with novel and promising functionalities. This tutorial review provides a useful guide to prepare ZIF-8 in its colloidal form, covering the published studies on the synthesis of homogeneous ZIF-8 particles with controlled size and shape. In addition, we present the most relevant advances in the development of colloidal ZIF-8 hybrid single-particles, reflecting the great potential an rapid development of this interdisciplinary research field. Finally, we highlight how formulation of ZIF-8 as colloids has led to the emergence of novel physicochemical phenomena that are useful for practical applications. This review aims promoting the development of MOFs as colloids, taking ZIF-8 as a pioneering and successful case that clearly shows the benefits of bridging MOF chemistry and colloidal science.

\section{Introduction}

The term colloid, derived from the Greek words kolla (glue) and eidos (like), was first introduced in 1861 by Thomas Graham, who referred to substances that, when in solution, are unable to diffuse across a permeable membrane. ${ }^{1}$ Graham attributed this behavior to the relatively larger size of the particles, which ranges from a few nanometers up to several microns. Thus, the dispersed particles in a colloid are larger than those in a true solution, yet small enough such that buoyancy and gravity are balanced, preventing the suspended particles from sinking or floating. Accordingly, colloids occupy an intermediate place between solutions and suspensions, making them highly amenable to specific applications. For instance, solid particles that form a colloidal system can flow like a liquid and therefore can be used in paints, inks, coatings, cosmetics, diagnostics or for drug delivery. ${ }^{2}$ Colloidal particles that are uniform in both size and shape can offer an additional level of functionality. For example, they can spontaneously self-assemble to form welldefined micro- or nano-hierarchical superstructures that exhibit enhanced or even novel properties. Therefore, the miniaturization of any substance, regardless of its chemical composition, to form colloidal particles of homogeneous siz

a. Catalan Institute of Nanoscience and Nanotechnology (ICN2), CSIC and Barcelona Institute of Science and Technology, Campus UAB, Bellaterra 08193, Barcelona,

Spain

b. ICREA, Pg. Lluís Companys 23, 08010 Barcelona, Spain and shape opens doors to materials with new functionalities and applications. A noteworthy example is the fabrication of metal-organic framework (MOF) particles in the colloidal size range.

MOFs are crystalline porous compounds based on metal ions or clusters connected by organic ligands, which can be designed into many different architectures and tailored for specific uses (e.g. adsorption, separation, catalysis, etc.) by adjusting their topology, pore size and/or chemical composition. Over the pas decade, growing interest in these materials has led to the discovery of useful synthetic tools that, beyond structural and compositional control, enable the production of MOF crystalline particles of uniform sizes and morphologies. ${ }^{3-6}$ This constitute a challenging but promising strategy to confer MOFs with colloidal properties ${ }_{\triangle}^{7}$ and therefore, with new functionalities for new applications.

In the above context, zeolitic imidazolate framework--8 (ZIF- \&) epitomizes the successful combination of MOFs and colloidal science. Zeolitic imidazolate frameworks are a subfamily of MOFs that present a crystalline topology like that of zeolites, characterized by large cavities connected through small windows (Fig. 1). Owing to the pioneering $\mathrm{ZIF}$ syntheses by Huang et. $a$ l and by Park et. al. in the early 2000s, researchers have expanded the ZIF family, which currently encompasses more than 150 reported structures. ${ }^{8,9}$ Among them, ZIF- 8 [Zn(2 $\mathrm{mim}_{2}$ ] (where 2-mim is 2-methylimidazole) has been widel| studied due to its large pore volume and surface area $(>1600$ $\mathrm{m}^{2} / \mathrm{g}$ ), high thermal and chemical stabilities, and ready synthesis: it can be prepared by simply mixing solutions of $\mathrm{Zn}$ (II)
Field Code Changed

Field Code Changed

Field Code Changed

Field Code Changed

Field Code Changed

Field Code Changed

Formatted: Font: Not Italic 


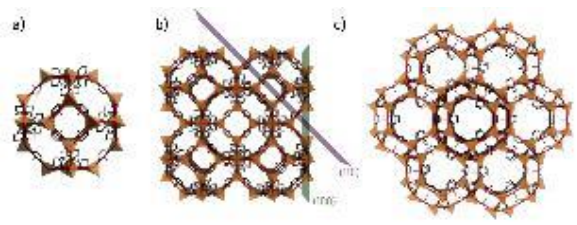

Fig. 1. a) Representation of the crystal structure of ZIF-8, revealing its cavity. b) Framework structure of ZIF-8, highlighting the [110] and [100] planes. c) Crystal structure of ZIF-8 along the [111] direction.

and 2-mim. Although initial research focused on the synthesis of ZIF-8 crystals in the micrometer-to-millimeter scale fo structural elucidation, the first synthesis of nanoscale ZIF-8, reported by Cravillon et al. in 2009, paved the way to colloida ZIF- $8 .{ }^{10}$ Synthesis of ZIF-8 has since rapidly evolved to enable production of colloidal crystals under a high degree of contro over size and morphology. Consequently, colloidal ZIF- 8 has been explored as a constituent in myriad new materials that combine the porosity-derived properties of MOFs with the advantages of colloids. Such work has illustrated how, for a given material, greater synthetic control can enable a wide range of applications. In this sense, ZIF- 8 has not only become new constituent of colloidal science but has also expanded the boundaries of crystal engineering. For example, the design of single-particle composites made of a diverse array of nanoparticles and biomolecules has opened new possibilities in fields such as photonics, biomedicine and catalysis. However full exploitation of the marriage of MOFs and colloidal science demands further research.

In this review, we cover research on ZIF-8 in colloidal form highlighting important lessons that will apply to future work on colloidal ZIFs, MOFs, and molecular crystals in general. Firstly, we discuss recent progresses in the synthesis of colloidal ZIF-8. Next, we address how the combination of colloidal ZIF- 8 crystals with other materials can yield new hybrid single-particles with new functionalities. Finally, we highlight the new physicochemical properties that arise from the controlled formulation of colloidal ZIF-8 crystals as well as their influence on the use of colloidal ZIF-8 for practical applications.

\section{Colloidal ZIF-8 crystals: size control}

In the synthesis of ZIF-8, as in every solution-phase crystallization, particle size is determined by the nucleation and growth rates. A higher nucleation rate corresponds to smaller particles, as the growth slows very early on, eventually stoppin due to a lack of nutrients. Consequently, formation of colloidal ZIF-8 nanocrystals will only succeed if the synthetic conditions favor nucleation over growth. In 2009, Cravillon et al. achieved the first synthesis of colloidal ZIF-8 (average particle size: $\sim 45$ $\mathrm{nm}){ }_{1}^{10}$ by simply stirring a mixture of $\mathrm{Zn}\left(\mathrm{NO}_{3}\right)_{2}$ and 2-mim in methanol (molar ratio $\mathrm{Zn}\left(\mathrm{NO}_{3}\right)_{2} / 2-\mathrm{mim} / \mathrm{MeOH}=1: 8: 1000$ ) at room temperature for 1 hour. They found that excess ligand was essential for promoting faster nucleation and stabilizing the initial colloids. This combination of excess ligand, methanol as solvent, and room temperature has since formed the basis for most syntheses of nanoscale ZIF-8 crystals. Additional reaction parameters (e.g. metal source, reaction time, molar ratio, reagent concentration and additive) can then be tuned to control the size and homogeneity of the desired colloidal ZIF-8 nanocrystals (Fig. 2). We discuss these parameters below. Schejn et al. studied the influence of the zinc salt used in the synthesis of ZIF-8. ${ }^{11}$ They observed that more-reactive metal precursors led to faster nucleation and consequently, to smal ZIF-8 particles: specifically, $\mathrm{Zn}(\mathrm{acac})_{2}$ gave nanocrystals whose average size was $45 \mathrm{~nm} ; \mathrm{Zn}\left(\mathrm{NO}_{3}\right)_{2}, 141 \mathrm{~nm} ; \mathrm{ZnSO}_{4}, 211 \mathrm{~nm}$; and $\mathrm{Zn}\left(\mathrm{ClO}_{4}\right)_{2}, 224 \mathrm{~nm}$. Contrariwise, less-reactive salts such as $\mathrm{Zn}\left(\mathrm{CH}_{3} \mathrm{COO}\right)_{2}, \mathrm{ZnCl}_{2}$, and $\mathrm{ZnI}_{2}$ yielded crystals with sizes varying between $300 \mathrm{~nm}$ and $500 \mathrm{~nm}$, and when the poorly reactive $\mathrm{ZnBr}_{2}$ was used, the crystals were even larger (ca. $1 \mu \mathrm{m}$ )

The relative and total concentrations of reagents strongly influence the size of the colloidal ZIF- 8 crystals. For instance, Zhang et al. were able to synthesize smaller ZIF-8 particles in methanol by increasing the $\mathrm{Zn}\left(\mathrm{NO}_{3}\right)_{2} / 2-\mathrm{mim} / \mathrm{MeOH}$ molar ratio from 1:4:500 to 1:16:500 (stirring, room temperature, 1 hour). ${ }^{12}$ The authors reported that the average particle size gradually decreased from $1 \mu \mathrm{m}$ to $100 \mathrm{~nm}$; however, an excess of 2-mim $(\mathrm{Zn} / 2-\mathrm{mim}=1: 16)$ resulted in aggregation of the ZIF-8 nanocrystals. Furthermore, Yeung et al. recently reported that for ZIF-8, increasing the reagent concentration led to a decrease in crystallization rate and consequently, to larger particles. ${ }^{13} \mathrm{For}$ example, by using a $\mathrm{Zn}\left(\mathrm{NO}_{3}\right)_{2} / 2-\mathrm{mim} / \mathrm{MeOH}$ ratio of 1:4:2500, ZIF-8 crystals of $41 \pm 19 \mathrm{~nm}$ were obtained, whereas larger particles with a broader size distribution $(717 \pm 267 \mathrm{~nm})$ were obtained using more concentrated solution with a $\mathrm{Zn}\left(\mathrm{NO}_{3}\right)_{2} / 2$ $\mathrm{mim} / \mathrm{MeOH}$ ratio of 1:4:250 (stirring, room temperature, 2 hours). They explained this phenomenon by assuming that there had been a pre-equilibrium of metastable intermediate clusters with different $\mathrm{Zn} / 2-\mathrm{mim}$ ratios. In this scenario, increasing the concentration would inhibit nucleation by favoring over-coordinated species, generating larger ZIF-8 particles.

Reaction time is another critical parameter for controlling the size and monodispersity of colloidal ZIF-8 crystals. Venna et al. (2010) studied the change in size of ZIF-8 particles synthesized over time upon mixing solutions of $\mathrm{Zn}\left(\mathrm{NO}_{3}\right)_{2}$ and 2-mim in $\mathrm{MeOH}$ (1:8:705) under stirring at room temperature. ${ }^{17}$ The authors observed that after an initial incubation period $(t<10$ minutes), a growth stage was reached during which the size of ZIF-8 increased, evolving from $\sim 50 \mathrm{~nm}$ spherical particles $(\mathrm{t}=10$ minutes) up to $230 \mathrm{~nm} \pm 40 \mathrm{~nm}$ ( $\mathrm{t}=30$ minutes). Then, the size remained constant and more-homogenous faceted crystals were formed $(230 \pm 20 \mathrm{~nm})$. At longer reaction times $(\mathrm{t}=12$ hours), larger $(500 \mathrm{~nm} \pm 40 \mathrm{~nm})$ crystals were produced showing a narrower size distribution at 24 hours. In 2018, Chocarro-Ruiz et al. proved that using a shorter reaction time yields smaller ZIF-8 particles. ${ }^{18}$ They reduced the average size of monodisperse ZIF-8 nanocrystals down to $32 \pm 5 \mathrm{~nm}$ by following a conventional synthetic procedure $\left(\mathrm{Zn}\left(\mathrm{NO}_{3}\right)_{2} / 2\right.$ $\mathrm{mim} / \mathrm{MeOH}=1: 8: 1000$, room temperature) but shortening the total reaction time to 7 minutes. After initial homogenization of

\section{Field Code Changed}

Field Code Changed

Field Code Changed

Field Code Changed

Field Code Changed

Field Code Changed

Field Code Changed 


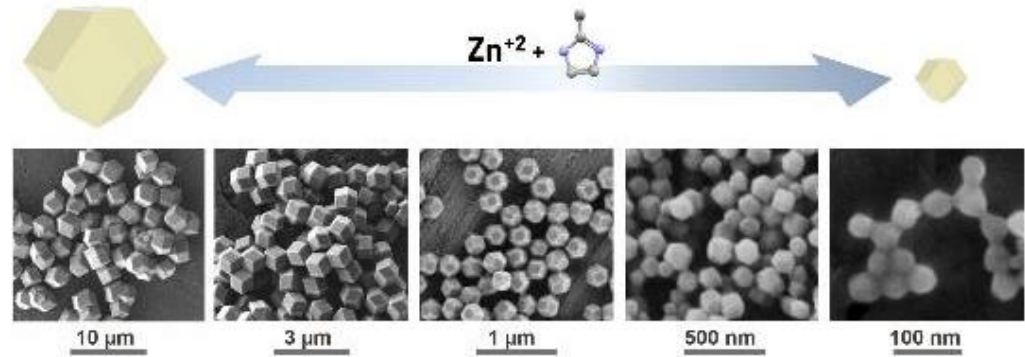

Fig. 2. Schematic of size control over ZIF-8 crystals (top). Field-emission scanning electron microscopy (FESEM) images of colloidal ZIF-8 particles (bottom) of $3 \mu \mathrm{m}, 1 \mu \mathrm{m}, 319$ $\mathrm{nm}, 147 \mathrm{~nm}$ and $38 \mathrm{~nm}$ in size (from left to right). ${ }^{14.16}$

the starting solutions, they left the mixture undisturbed. This effect was also observed by Cravillon et al., ${ }_{14}^{14}$ who obtained a narrow size distribution of ZIF- 8 crystals only when they did no stir the reagent solutions; they suggested that the polydispersity associated with stirring may have resulted from secondary nucleation caused by turbulence.

In the context of MOF synthesis, one of the most commo strategies to achieve well-defined size crystals is to incorporate additives, also known as modulators, that can affect the nucleation and growth rates. ${ }^{19,20}$ Modulators act as cappin ligands that compete with the organic linker, reducing the number of nucleation points (thus, increasing the crystal size) and, conversely, limiting the crystal growth (thus, decreasing the crystal size). Given these opposing effects, the net effect of a modulator depends on its coordination strength to the metal, its concentration and its basicity. In 2011, Cravillon et al. evaluated the effects of different modulators (formate, 1 methylimidazole and $n$-butylamine) in the synthesis of ZIF-8 in methanol, ${ }^{14}$ using a $\mathrm{Zn}\left(\mathrm{NO}_{3}\right)_{2} / 2-\mathrm{mim} / \mathrm{L} / \mathrm{MeOH}(\mathrm{L}=$ modulator) molar ratio of 1:4:4:1000 and a reaction time of 24 hours at room temperature. The authors observed that in the presence of formate or 1-methylimidazole, monodisperse microcrystals (1 $\mu \mathrm{m}$ to $3 \mu \mathrm{m}$ ) were formed (Fig. 2). However, when $n$ butylamine was employed, the average size was $18 \mathrm{~nm}$ Moreover, they demonstrated that by varying the compositions of the reagent solutions with $n$-butylamine, they could tune the nanocrystal size between $9 \mathrm{~nm}$ and $65 \mathrm{~nm}$. They attributed this behavior to the higher basicity of $n$-butylamine, which can deprotonate the intermediate $\mathrm{Zn}: 2$-mim species to accelerate the nucleation rate. Contrariwise, formate and 1 methylimidazole, which are less basic, cannot deprotonate the intermediate, and instead, compete with 2-mim, thus leading to a low nucleation rate and consequently, to larger crystals. Furthermore, in 2013, Yanai et al. found that using 1 methylimidazole as modulator, the crystal size decreases with increasing concentrations greater than $100 \mathrm{mM}$, due to suppression of both nucleation and crystal growth. ${ }^{21}$ Thus, to produce larger monodisperse ZIF-8 crystals, the author explored the use of a relatively weaker ligand, polyvinylpyrrolidone (PVP), which ultimately helped to furthe decrease the number of nucleation points without suppressing crystal growth. By using both 1-methylimidazole and PVP, they could synthesize highly monodisperse ZIF- 8 crystals of $\sim 5 \mu \mathrm{m}$ in size.

Although most work on the synthesis of colloidal ZIF- 8 has been done in methanol, much effort has been devoted to using wate as solvent, both for the inherent advantages of aqueous chemistry (e.g. safety, biological compatibility and low cost) a well as for the possibility that water could enable better control over the size and homogeneity of nanoscale ZIF-8 crystals. For example, using water as the solvent facilitates the use of surfactants, which have been demonstrated to help contro colloidal ZIF-8 (vide infra). However, aqueous synthesis of ZIF-8 is not trivial, as it can generate by-products or amorphous compounds. Kida et al. reported a study on the influence of reaction parameters such as metal/ligand ratio, concentration and reaction time on the size of ZIF-8 particles synthesized in water. ${ }^{22}$ They observed similar trends as those observed for methanol. For instance, when they increased the $\mathrm{Zn}\left(\mathrm{NO}_{3}\right)_{2} / 2$ mim ratio from 1:40 to 1:100, the average crystal size decreased from $2 \mu \mathrm{m}$ to $250 \mathrm{~nm}$ and the size distribution narrowed. The authors also investigated the total concentration of reagents and found that high concentrations $\left(\mathrm{Zn}\left(\mathrm{NO}_{3}\right)_{2} / 2-\mathrm{mim} / \mathrm{H}_{2} \mathrm{O}=\right.$ $1: 20: 895)$ were required to form crystalline $\mathrm{ZIF}-8$, but that higher concentrations led to aggregation of smaller particles. Finally, upon exploring reaction times ranging from 5 minutes to 24 hours, they observed that ZIF- 8 crystals exhibited a simila size of $\sim 500 \mathrm{~nm}$.

\section{Colloidal ZIF-8 crystals: shape control}

Morphologically, ZIF-8 crystals are characterized as being rhombic dodecahedral (RD), truncated rhombic dodecahedral (TRD) or, to a lesser extent, cubic, as crystal growth begins with formation of an all [100]-oriented cube that gradually becomes TRD and finally, RD (Fig. 3). ${ }^{23}$ The final RD shape of ZIF-8 results from Wulff's rule, whereby the slowest growing direction (for ZIF-8, [110]) determines the final shape and the most thermodynamically stable facet orientation. Here, $R D$ refers to

\section{Field Code Changed}

Commented [C1]: I think this figure 2 can be reinforced by addin below the SEM line, some arrows with labels "Concentration of below the SEM line, some arrows with labels "Concentration of "Reactivity of Zn salt" and etc, concordant with their effect on the size. This could help the people to follow very easily what we say in general in this size control section.

Field Code Changed

Field Code Changed

Field Code Changed

\section{Field Code Changed}

Field Code Changed
Field Code Changed

Field Code Changed 
a polyhedral shape with twelve rhombus-shaped facets, whereas the term truncated is used to indicate polyhedron with cut vertices. For ZIF-8 having SOD topology, the RD shape comprises twelve equivalent rhomboid (or tetragonal) facets that are all [110]-oriented. Alternatively, the TRD shape is an RD with square cuts (truncations) in the six [100] vertices. This TRD shape comprises twelve irregular hexagonal facets that ar [110]-oriented and six square facets that are [100]-oriented. Finally, the cubic shape is a cube with six facets that are all [100] oriented. Overall, the cubic and TRD shapes of ZIF-8 can be considered to be the result of "unfinished" crystal-growth, as nicely demonstrated by Cravillon et al. ${ }^{14}$

Given the aforementioned crystal-growth process, controlle synthesis of homogeneous RD, TRD or cubic ZIF-8 crystals requires selective growth of specific crystalline facets. A common approach for achieving such control in nanomateria synthesis is the use of surfactants, which can preferentially ge adsorbed onto certain crystalline facets to act as growth inhibitors or capping agents. ${ }^{27}$ Additionally, surfactants adsorbed onto the surface of nanoparticles also protect them from aggregation, thus facilitating the formation of stable colloids. In 2011, Pan et al. were the first to demonstrate that surfactants could also be used to control the preferential growth of specific crystalline facets of MOFs (in this case, ZIF8). ${ }^{28}$ They used cetyltrimethylammonium bromide (CTAB) as capping agent to isolate pure cubic or TRD ZIF-8 crystals. They heated an aqueous solution of $\mathrm{Zn}\left(\mathrm{NO}_{3}\right)_{2}, 2-\mathrm{mim}\left(\mathrm{Zn} / 2-\mathrm{mim} / \mathrm{H}_{2} \mathrm{O}\right.$ $=1: 55: 4440)$ and $C T A B$ at $120 \stackrel{\circ}{ } \mathrm{C}$ for 6 hours. They found that CTAB molecules preferentially attach onto the energeticallyfavorable [100] facets, owing to their hydrophobic tail. Consequently, when CTAB was used, crystal growth in the [100] direction drastically slowed down, enabling the authors to isolate homogeneous cubic or TRD crystals before the RD shape had been reached. Consistent with their hypothesis, the author showed that the use of a relatively low concentration of CTAB $(0.025 \mathrm{mg} / \mathrm{mL})$ provided TRD ZIF-8 crystals, whereas increasing

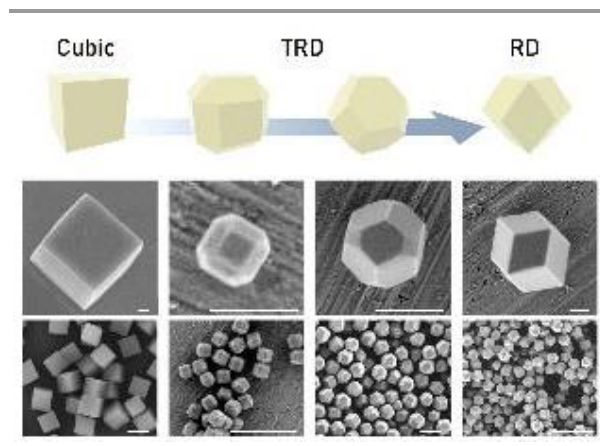

Fig. 3. Schematic of the morphologic evolution of ZIF-8 crystals, from cubic to truncated dodecahedra (TRD) to rhombic dodecahedra (RD) (top). FESEM images of colloidal ZIF-8 crystals of cubic, TRD or RD morphology (middle and bottom). Scale bars: $250 \mathrm{~nm}$ (middle) and $1 \mu \mathrm{m}$ (bottom). $15,24-26$ the concentration up to $0.1 \mathrm{mg} / \mathrm{mL}$ afforded cubic crystals. Interestingly, the use of analogous surfactants having a simila hydrocarbon tail (e.g. cetyltrimethylammonium chloride (CTAC) and trimethylstearylammonium chloride (STAC)) enabled a similar level of morphologic control. However, this strategy could not be used for the synthesis of ZIF-8 in methanol, as surfactants do not efficiently attach onto the facets of ZIF- 8 particles in methanol. In 2015, Tanaka et al. reported the synthesis of homogeneous cubic ZIF-8 crystals based on stirring an aqueous solution of $\mathrm{Zn}\left(\mathrm{CH}_{3} \mathrm{COO}\right)_{2}$, 2-mim and CTAC $(\mathrm{Zn} / 2$ $\left.\mathrm{mim} / \mathrm{H}_{2} \mathrm{O}=1: 60: 2220\right)$ with a low concentration of CTAC $(0.064$ $\mathrm{mg} / \mathrm{mL}$ ). ${ }^{29}$ In 2018, our group refined the above synthetic protocol to control the truncation degree of highly monodisperse TRD ZIF-8 crystals (polydispersity: $<5 \%$ ). ${ }^{15}$ We left an aqueous solution of $\mathrm{Zn}\left(\mathrm{CH}_{3} \mathrm{COO}\right)_{2}, 2$-mim and $\mathrm{CTAB}$ $\left(\mathrm{Zn} / 2-\mathrm{mim} / \mathrm{CTAB} / \mathrm{H}_{2} \mathrm{O}=1: 20: 4: 400\right)$ undisturbed at room temperature for 2 hours. Following this protocol, we could modulate the truncation of TRD ZIF- 8 crystals by slightly varying the 2-mim $/ \mathrm{H}_{2} \mathrm{O}$ molar ratio and the amount of CTAB. Overall, lower 2-mim/ $\mathrm{H}_{2} \mathrm{O}$ molar ratios and higher concentrations of CTAB afforded greater truncation. We also found that TRD ZIF8 particles with lower truncations (close to the RD shape) could be prepared without the use of CTAB, if the incubation times were kept short. For example, TRD ZIF-8 crystals with a truncation level of 0.38 were synthesized by simply incubating an aqueous solution of $\mathrm{Zn}\left(\mathrm{CH}_{3} \mathrm{COO}\right)_{2}$ and $2-\mathrm{mim}\left(\mathrm{Zn} / 2-\mathrm{mim} / \mathrm{H}_{2} \mathrm{O}\right.$ $=1: 13: 460)$ for 15 minutes at room temperature. Note that when we incubated the solution for longer ( 2 hours), we obtained homogeneous RD ZIF- 8 crystals, as we had expected. The importance of the concentration of CTAB in shaping colloidal ZIF-8 particles was also reported by Yang et al. in 2018 (Fig. 4) ${ }^{30}$ Briefly, these authors expanded the available morphologies of ZIF-8 particles to octagonal plates, interpenetration twins and nanorods by further tuning the concentration of $C T A B$ in a synthesis that comprised heating an aqueous solution of $\mathrm{Zn}\left(\mathrm{CH}_{3} \mathrm{COO}\right)_{2}, 2$-mim and CTAB $(\mathrm{Zn} / 2$ $\mathrm{mim} / \mathrm{H}_{2} \mathrm{O}=1: 30: 1800$ ) at 120 ㅇ $\mathrm{C}$ for 24 hours. The ZIFmorphology depended on the CTAB concentration: $0.16 \mathrm{wt} \%$ gave octagonal plates; $0.24 \mathrm{wt} \%$, interpenetration twins; and 0.35 wt \%, anisotropic nanorods. The authors highlighted the 2 $\mathrm{mim} / \mathrm{H}_{2} \mathrm{O}$ molar ratio as another tunable parameter for obtaining well-defined shapes.

The fact that surfactants such as CTAB can preferentially attach onto [100] facets to influence ZIF-8 crystal-growth suggested that if surfactants which preferentially attach onto other facets were discovered, they could provide access to other morphologies. Along these lines, Hong et al. discovered that tris(hydroxymetyl)aminomethane (TRIS) preferentially stabilizes the [111] facets. They synthesized ZIF-8 at room temperature using a similar procedure to one previously described, ${ }^{15}$ expectexcept that they replaced CTAB with TRIS, obtaining octahedral, flake-shaped or flower-like ZIF-8 superstructures depending on the TRIS concentration. Remarkably, when they used a combination of CTAB and TRIS, they obtained hexapod-like and burr puzzle-like ZIF-8 superstructures (Fig. 4). ${ }^{31}$
Commented [C3]: Although there is no clear proof, this is because of the higher solubility of CTAB in methanol.

\section{Field Code Changed \\ Field Code Changed \\ Field Code Changed}

Field Code Changed

Field Code Changed

Field Code Changed

Commented [C2]: In fig.3, the $3^{\text {rd }}$ shape (TRD) can be oriented in the same way as the $2^{\text {nd }}$ shape. It is a bit confusing. It's also not oriented with the $4^{\text {th }}$ shape.

\section{Field Code Changed}

Commented [C4]: In Fig 4, you kind of want to know how the morphology is changing even though the same surfactant is used. Something to imply that the surfactant concentration is effecting the size can be added.

Or, the figure can be re-organized simply as 3 groups of shapes obtained by i)CTAB ii)TRIS iii) CTAB+TRIS, instead of having multiple arrows labelled "CTAB", "TRIS" or "CTAB+TRIS" for each shape.

Also, I believe that the cubes and at least one kind of TRD should also be added as the figure looks like a "bank of shapes" you can obtain with surfactants.

Field Code Changed

Field Code Changed

Field Code Changed 
In addition to the aforementioned bottom-up strategies to control the shape of ZIF- 8 particles are, there are also top-down strategies, whereby the morphology of ZIF- 8 particles is altered post-synthetically (Fig. 5). For example, some unprecedentedly shaped, hierarchically porous or simply hollow ZIF-8 crystals have been obtained using methods such as wet-chemical etching and sacrificial templating (Fig. 5, top). Such top-down shaping approaches require a mechanism that selectively and controllably sculpts the pre-synthesized ZIF-8 crystals. In 2015 our group proved that anisotropic wet-chemical etching could be applied to ZIF- 8 particles to re-shape them into cubic, tetrahedral or hollow-box-shaped colloidal ZIF-8 crystals, similarly to what had previously been described for inorganic nanoparticles. Thus, we incubated $\mathrm{ZIF}-8$ particles into an acidified/basified xylenol orange (XO) solution that simultaneously acts as etchant and chelating agent. ${ }^{26}$ The $X O$ solution sequentially protonated the 2 -mim ligands, breaking the $\mathrm{Zn}(\mathrm{II})-2-\mathrm{mim}$ coordination bonds and sequestering the liberated $\mathrm{Zn}(\mathrm{II}) / \mathrm{Co}$ (II) ions to form water soluble metal-XO complexes. We found that TRD particles could be etched into cubic particles, as the etching rate in the [100] direction was faster than in the [110] direction; somehow reverting the crysta growth described above. When we exposed RD ZIF-8 particles to a $\mathrm{XO}$ solution at $\mathrm{pH}=3.5$, we obtained tetrahedral ZIF-8 particles, which we attributed to faster etching along the [100] and [211] directions (the vertices and edges of the RD respectively) relative to the [110] direction (the facets of the $\mathrm{RD}$ ). Remarkably, by decreasing the $\mathrm{pH}$ to 2.5 , we were able to slow down the etching along the [100] direction, which in turn provided hollow ZIF-8 boxes. ${ }^{32}$ Alternatively, Hu et al. showed that etching of the internal core of ZIF-8 particles to form hollow ZIF-8 particles could be achieved using tannic and gallic acids. ${ }^{33}$ In their proposed mechanism, the protons generated by the tannic/gallic acid protonated the 2-mim, cause the disassembly of the framework, and then dissolve the core of the ZIF-8 particles. The authors reasoned that due to the large molecular size of these acids, they blocked the pores of the externa surface of the ZIF-8 particles, thereby providing surface protection against etching.

Lee et al. obtained spherical hollow ZIF-8 particles by a template-assisted method using polystyrene spheres as sacrificial template. ${ }^{36}$ Firstly, they added carboxylateterminated polystyrene spheres to a solution of $\mathrm{Zn}\left(\mathrm{NO}_{3}\right)_{2}$ and 2 $\mathrm{mim}$ in methanol. With this incubation, the crystallization of ZIF8 occurred on the surface of the polystyrene spheres, yielding spherical core-shell polystyrene@ZIF-8 particles. Then, they

\section{Field Code Changed}

Field Code Changed

Commented [C5]: For zif- 8 it is only acidified.

Field Code Changed

Field Code Changed

Commented [C6]: Can be replaced with "faster than in any othe direction"

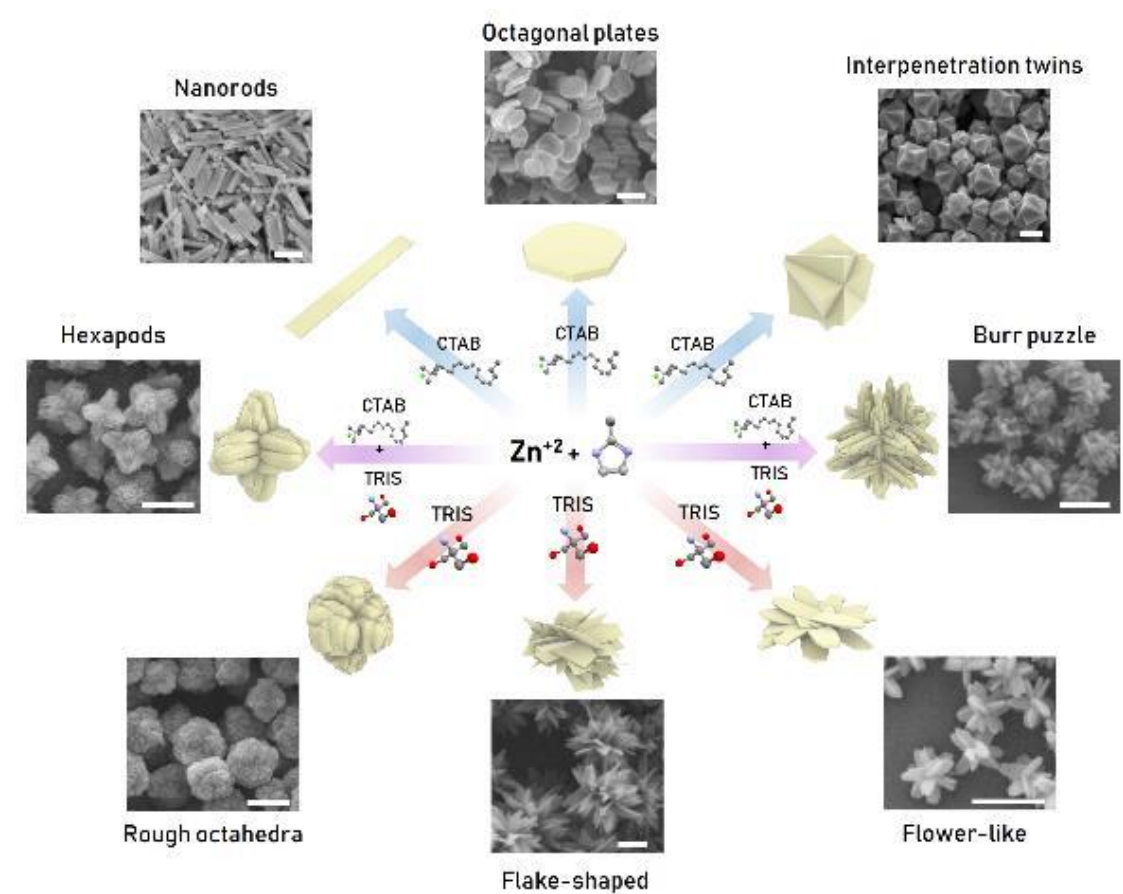

Fig. 4. Schematic showing the influence of different surfactants on the crystal morphology of colloidal ZIF-8, with the corresponding FESEM images for each of the discovered morphologies. Scale bar (all micrographs): $1 \mu \mathrm{m} \cdot{ }^{30,31}$ 
treated the polystyrene@ZIF-8 particles with DMF, which selectively dissolved the polystyrene polymer to afford hollow spherical ZIF-8 particles. Seeking to increase the complexity of ZIF-8 particles, Shen et al. recently developed another template strategy involving polystyrene spheres. They synthesized ZIF-8 crystals (size: $1 \mu \mathrm{m}$ to $4 \mu \mathrm{m}$ ) with ordered internal macropore by soaking a solution of ZIF-8 precursors in an ordered monolithic superstructure comprising polystyrene spheres. ${ }^{34}$ During incubation, they added a mixture of ammonia/methano to induce in situ crystallization of ZIF-8 inside the superstructure. Interestingly, instead of obtaining the continuous monolithic polystyrene@ZIF-8 superstructure that they expected, they observed formation of some polyhedra crystals with exposed [111], [100] and [110] facets. Finally, they exposed these crystals to THF to remove the polystyrene template, which yielded hierarchically porous ZIF-8 particles with ordered macropores (pore size: $\sim 270 \mathrm{~nm}$ ) (Fig. 5, middle). Among the various template-assisted methods to shape ZIF- 8 particles, several self-sacrificial template methods have been developed (Fig. 5, bottom). For example, Chou et al. produced hollow ZIF-8 particles via "double-solvent mediated overgrowth". In this strategy, pristine ZIF-8 particles (average size: $200 \mathrm{~nm}$ ) produced in water were used as seeds to grow another layer of ZIF-8 on top of them in methanol, leading to a final size of $450 \mathrm{~nm} \cdot{ }^{37}$ They realized that the inner water-loade ZIF-8 cores became disassociated and dissolved after ageing in methanol, ultimately leaving behind well-shaped hollow ZIF-8 particles. They proposed that the $\mathrm{pH}$ of the internal wate environment drops due to deprotonation of the 2-mim in the external methanol environment during formation of the ZIF-8 shell. Alternatively, Zhang et al. used a similar tannic acid-based approach to construct yolk-shelled ZIF-8 and bimetallic $\mathrm{Zn} / \mathrm{Co}$

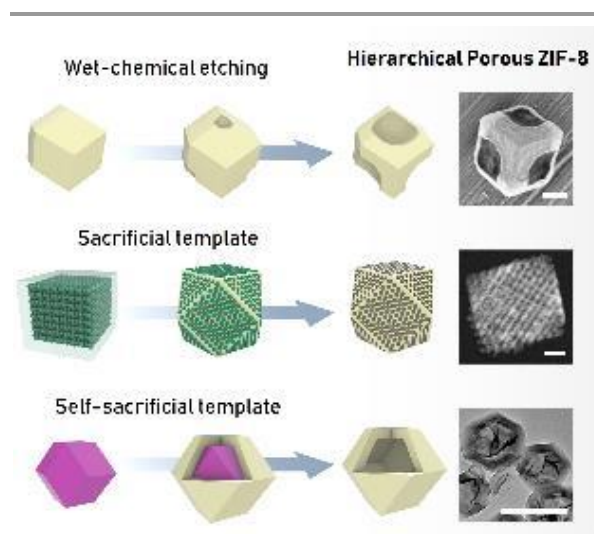

Fig. 5. Illustration of the top-down strategies to post-synthetically tune the morphology of RD colloidal ZIF-8 crystals (left), and the corresponding FESEM images of the resulting ZIF-8 crystals for each strategy (right). Scale bar (all micrographs): $500 \mathrm{~nm}_{2}^{26,3,4,35}$
ZIF particles from pre-synthesized RD ZIF-8 particles. ${ }^{38,39}$ Another self-sacrificial templating strategy, based on the different stability of isostructural ZIF-8 and ZIF-67, has been developed by Yang et al. and Chen et al. The researchers first prepared composite particles containing ZIF- 67 and ZIF- 8 , and then placed the resultant core-shell ZIF-67@ZIF-8 particles in hot methanol to sacrifice the less stable ZIF-67 portion, which afforded newly shaped pure ZIF-8 particles. ${ }^{40,35}$

\section{Single-particle ZIF-8 composites}

Combining colloidal ZIF-8 crystals with other materials yields functional composites that can exhibit new properties. Given that the highly stable microporous structure of ZIF-8 can be easily generated under mild conditions in a controlled manner single-particle ZIF- 8 composites can be readily prepared. The ability to form ZIF-8 crystals of uniform size and shape offers the possibility to impart the colloidal nature of ZIF-8 to functional single-particle ZIF-8 composites. The reported methodologies for constructing single-particle ZIF-8-based hybrid materials can generally be divided into two categories: encapsulation of guest materials during in situ formation of ZIF-8 colloidal crystals (bottom-up); and post-synthetic hybridization of presynthesized colloidal ZIF-8 with functional materials (postsynthetic)

\section{Bottom-up approaches for single-particle ZIF-8 composites}

The high degree of control over the synthesis of ZIF- 8 crystals enables localization of nucleation and subsequent growth around functional guests, creating composites unattainable by other techniques such as guest infiltration, surface adsorption or covalent linkage. This in situ (or de novo) encapsulation strategy has emerged as a simple, fast and versatile method whose advantages include high loading efficiency, low leaching, and unlimited cargo size. Interestingly, the possibility of encapsulating large cargo molecules (i.e. larger than the host pores) in a host of controlled size and shape that exhibits exceptional stability and negligible cytotoxicity, has positioned ZIF-8 as among the most attractive porous materials for colloidal bio-composites. The first example of the in situ encapsulation of functional guest into ZIF-8 crystals was reported in 2012 by Lu et al., ${ }^{41}$ who developed a strategy based on functionalization of nanoparticle surfaces with PVP for controlled encapsulation of various inorganic nanoparticles of different sizes, shapes and compositions. They successfully encapsulated $\mathrm{Pt}, \mathrm{CdTe}$ and $\mathrm{Fe}_{3} \mathrm{O}_{4}$ nanoparticles (NPs), lanthanide-doped $\mathrm{NaYF}_{4}$ nanoparticles, Ag cubes, polystyrene spheres, and lanthanide-doped $\mathrm{NaYF}_{4}$ or $\beta$-FeOOH rods. Formation of these NP@ZIF-8 composites was based on continuous adsorption of the functionalized nanoparticles onto the surface of the ZIF- 8 crystals in formation. This was achieved by mixing methanolic solutions of $\mathrm{Zn}\left(\mathrm{NO}_{3}\right)_{2}$ and 2-mim with a suspension of the desired PVP-functionalized NPs, also in methanol, and then leaving the mixture to react for 24 hours at room temperature without stirring. The amphiphilic nature of PVP was crucial for stabilizing the nanoparticles as well as for

\section{Field Code Changed \\ Field Code Changed}

Field Code Changed

Field Code Changed

Field Code Changed

Commented [C7]: This was my personal comment in my thesis,

they don't say something like this in their paper.

Field Code Changed

Field Code Changed

Field Code Changed

Field Code Changed

Field Code Changed 
favoring the affinity between the nanoparticles and the ZIF-8 crystals. Another example that illustrates the importance of functionalization of nanoparticles to promote surface nucleation and growth of ZIF-8 is the synthesis of single-particle NP@ZIF-8 composites by Zheng et al. in 2016. ${ }^{42}$ The authors first synthesized plasmonic nanoparticles of different sizes, shapes and compositions (Au nanorods, Au@Ag core-shell nanorods and Au nanostars), stabilized them with quaternary ammonium surfactants (CTAB or CTAC) and finally, induced nucleation and growth of ZIF- 8 crystals on the metal surface. Remarkably, they could tune the thickness of the ZIF- 8 shell by varying the reaction time or $C T A B$ concentration. Interestingly, although capping agents can be valuable in the synthesis of NP@ZIF-8 materials, their presence may affect the performance of the embedded NPs, leading some researchers to avoid their use. In
2013, Wang et al. reported encapsulation of highly disperse Pt nanoparticles into colloidal ZIF-8 crystals to form Pt@ZIF-8 composites without the use of any capping agent. ${ }^{43}$ Their twostep method comprised treatment of unprotected Pt NPs with 2-mim as ligand under ultrasonication, followed by addition of zinc nitrate. In this process, the methyl imidazole both stabilizes the Pt NPs and acts as the nucleation site.

Apart from inorganic nanoparticles, target organic molecules such as dyes, drugs and therapeutic agents can be efficiently encapsulated inside of the ZIF-8 framework via bottom-up approaches. For instance, in 2012, Liédana et al. reported a comparative study on the encapsulation efficiency of caffeine in ZIF-8 via in situ and ex situ encapsulation strategies, demonstrating that in situ encapsulation was more rapid and efficient, as it yielded caffeine@ZIF-8 composites with higher
Field Code Changed

Field Code Changed

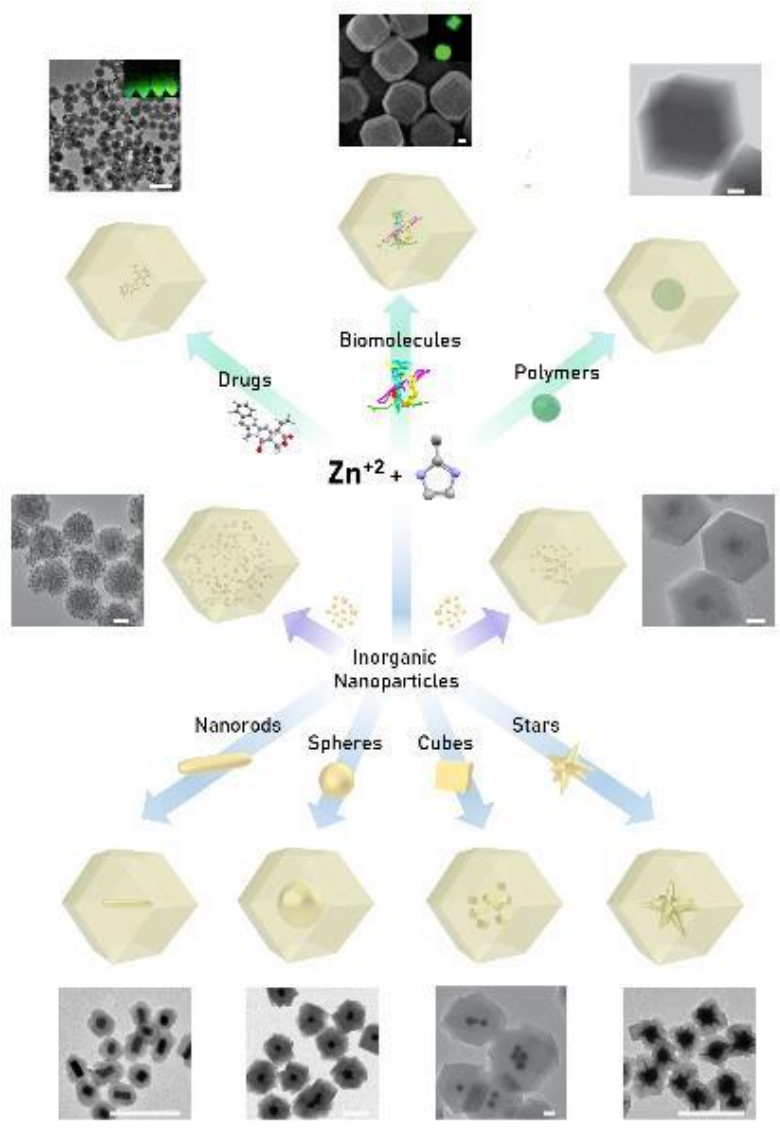

Fig. 6. Illustration showing the in situ encapsulation of biomolecules (top) and inorganic nanoparticles (bottom) within the ZIF-8 structure and the corresponding electron microscopy images (TEM or FESEM) for each of the composites. Scale bars (all micrographs): $250 \mathrm{~nm}_{2}^{41,42,45}$

Field Code Changed

Field Code Changed

Field Code Changed 
guest loading ( $c a .28 \mathrm{wt} \%$ ) and enabled controlled release of the guest. ${ }^{44}$ The simplicity and efficacy of in situ encapsulation have fostered its use in the synthesis of various colloidal drug loaded ZIF-8 materials. For example, 2014, Zhuang et al. reported the encapsulation of fluorescein (1 wt \%) or the anticancer drug camptothecin ( $2 \mathrm{wt} \%$ ) in $\mathrm{ZIF}-8$, by mixing the appropriate $\mathrm{ZIF}-8$ precursors in the presence of these guest molecules. ${ }^{45}$ In 2016, Zheng et al. discovered that target molecules that exhibit coordinating functional groups could form coordination polymers with $\mathrm{Zn}$ (II) ions that, upon addition of 2-mim, disassemble. ${ }^{46}$ Subsequent formation of ZIF-8 resulted in micro/mesostructured MOF crystals with loadings of up to $20 \mathrm{wt} \%$.

The possibility to produce colloidal ZIF- 8 under strict control and in very mild synthetic conditions (i.e. water, room temperature) enables construction of MOF-based protective coatings for biomacromolecules via in situ encapsulation. In 2014, Lyu et al. reported the first such example of a biomacromolecule being embedded into ZIF-8. ${ }^{47}$ They first stabilized cytochrome protein (Cyt c), mixed it with PVP and then, introduced the PVP modified Cyt c into a solution of $\mathrm{Zn}$ (II) and 2-mim. Then, the mixture was incubated at room temperature for 24 hours without stirring to obtain the desired Cyt $c @ Z I F-8$ composite. The authors found that they could encapsulate Cyt $c$ this way even without using PVP, suggesting that the strong interaction between $\mathrm{Zn}$ (II) and the amide groups of the protein favors formation of Cyt c@ZIF-8. One year later, the same group extended their method to the co-embedding of two enzymes into ZIF-8. ${ }^{48}$ Thus, they encapsulated glucose oxidase and horseradish peroxidase within ZIF-8 in aqueous solution without adding any capping agent. Interestingly, embedding th two enzymes simultaneously provided a synergetic effect: the resulting composite was highly efficient at catalyzing a cascade reaction. That same year, inspired by natural biomineralization processes, Liang et al. demonstrated that colloidal ZIF-8 could be employed as protective coatings for various biomacromolecules, including ovalbumin, ribonuclease $A$ human serum albumin, pyrroloquinoline quinone-dependent glucose dehydrogenase, lipase, hemoglobin, lysozyme, insulin horseradish peroxidase, trypsin, urease and oligonucleotides. ${ }^{49}$

They proposed that the existing interactions between biomacromolecules and the MOF precursors increases the concentration of the building blocks around the biomacromolecules, thereby inducing MOF nucleation. The formation of these composites was achieved by mixing an aqueous solution of $\mathrm{Zn}\left(\mathrm{CH}_{3} \mathrm{COO}\right)_{2}$ with an aqueous solution of 2-mim containing the appropriate biomolecule, and keeping the resulting mixture undisturbed for 12 hours at room temperature. After encapsulation, several of these biomacromolecules maintained their activity, even after having been exposed to extreme environments. Recently, the same group investigated the biomimetic mineralization of ZIF-8 by diverse array of simple sugars and carbohydrates. ${ }^{50}$ The authors found that chemical functionalization of carbohydrates (e.g. carboxylation) caused an increase in the concentration of $\mathrm{Zn}(\|)^{+2}$-at the carbohydrate surface, due to Coulombic attraction between the functional groups and the $\mathrm{Zn}$ cations, which ultimately favored rapid formation of ZIF-8. They determined the optimal condition for quantitative $(100 \%)$ encapsulation of the model carbohydrate therapeutic $\mathrm{CM}$-dextran and its subsequent controlled release, triggered by addition of ethylenediaminetetraacetic acid. Earlier this year, Feng et al. demonstrated that this protectivecoating strategy could be exploited for encapsulation of antibodies, achieving very high encapsulation efficiencies (> 99\%) for human immunoglobulin polyclonal antibody, goat antiBSA IgG polyclonal antibody and the monoclonal antibody adalimumab. ${ }^{51}$ The antibody@ZIF composites exhibited enhanced resistance against perturbation environments, such as heating, organic solvents, and mechanical pressure; were amenable to long-term storage ( $>3$ weeks) under temperaturecycling test conditions $\left(4 \circ \mathrm{C} \leftrightarrow 50^{\circ} \mathrm{C}\right)$ at a fast ramp rate $\left(25^{\circ} \mathrm{C}\right.$ $\left.\mathrm{min}^{-1}\right)$; and allowed for quick recovery of the antibodies before use.

\section{Post-synthetic single-particle ZIF-8 composites}

While the aforementioned approaches focused on encapsulation of functional guests within colloidal ZIF-8 crystals, guest molecules can also be positioned along the outer surface of such crystals. For example, in 2013, Li et al. reported the preparation of ZIF-8@Au hybrid composites. They started from colloidal ZIF-8 crystals, creating a single layer of Au NPs that were uniformly distributed on the crystal surface (Fig. 7 left). ${ }^{52}$ The authors devised two strategies: post-growth attachment and on-site reduction. In the former, they prepared Au NPs, stabilized them with 3-mercaptopropionic acid (MPA) and then added the stabilized NPs to ZIF-8 crystals. In the second method, they mixed an Au-MPA complex with colloidal ZIF-8 crystals, and then reduced the resultant composites to obtain Au NPs. In both strategies, coordination between the MPA and the Zn(II) ions of the ZIF- 8 crystals enabled localization

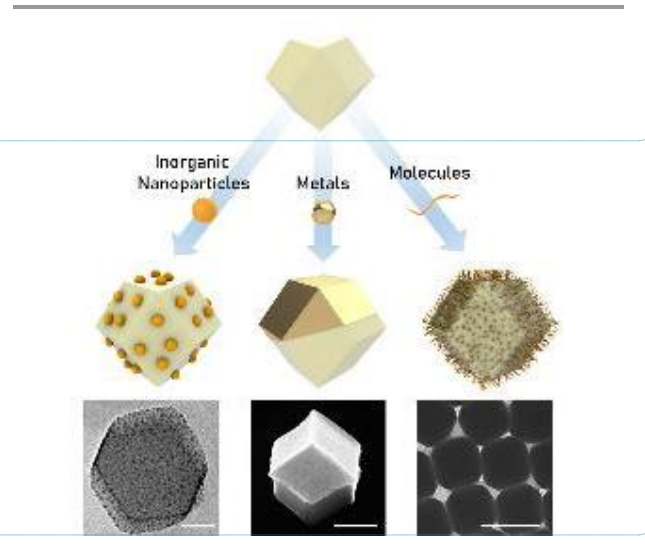

Fig. 7. Schematic on the versatility of the post-synthetic functionalization of colloidal ZIF-8 crystals with inorganic nanoparticles (left), metal coatings (centre) or polymers (right), and the corresponding electron microscopy images (bottom row). Scale bars: $20 \mathrm{~nm}$ (left) and $500 \mathrm{~nm}$ (center and right). $52,54,5,5$
Field Code Changed

Field Code Changed

Field Code Changed

Field Code Changed

Field Code Changed

Field Code Changed

Field Code Changed

Field Code Changed

Field Code Changed

Field Code Changed

Field Code Changed

Field Code Changed 
of Au NPs on the crystal surface. However, the authors found that on-site reduction minimized aggregation and enlargement of Au NPs, due to the surface-pinning effect of MPA. One year later, He et al. reported a straightforward method for the fabrication of yellow fluorescent ZIF-8@GSH-Au (GSH-Au = glutathione-Au nanoclusters) single-particle composites that involved directly mixing GSH-Au with the synthesized colloidal ZIF- 8 crystals at room temperature in methanol, followed by 12 hours of stirring..$^{53}$ The authors attributed formation of the ZIF8@GSH-Au composites to coordination interactions between the $\mathrm{Zn}$ (II) ions and the GSH on the nanocluster surface. In 2016, our group reported a strategy to fabricate Janus particles by partially coating ZIF-8 crystals (Fig. 7, middle). ${ }^{54}$ Our method is based on direct evaporation of metals ( $\mathrm{Au}, \mathrm{Co}$ or $\mathrm{Pt}$ ) on the surface of ZIF-8 crystals, previously immobilized onto planar surfaces, to yield an asymmetric structure in which the metalfilm thickness can be controlled. We showed that colloidal Janus ZIF-8@Pt particles could behave as motors when immersed in a solution of sodium cholate and $\mathrm{H}_{2} \mathrm{O}_{2}$ in aqueous ethanol.

Colloidal ZIF-8 crystals have been surface-functionalized with cargo other than inorganic nanoparticles. For example, the outer functionalization of ZIF-8 crystals with $\mathrm{SiO}_{2}$ has been explored for the fabrication of colloidal ZIF-8@ $\mathrm{SiO}_{2}$ composites. Thus, in 2014, He et al. coated homogenous rhombic dodecahedral ZIF-8 nanocrystals with $\mathrm{SiO}_{2}$ by following a sol-gel process which involved alkaline-catalyzed hydrolysis and condensation of tetraethyl orthosilicate in ethanol, leading to formation of core-shell ZIF-8@ $\mathrm{SiO}_{2}{ }^{56}$ In 2017, Wu et al prepared superhydrophobic core-shell ZIF-8@SiO ${ }_{2}$ composites using a two-step approach. ${ }^{57}$ First, they coated colloidal ZIF-8 nanocrystals with $\mathrm{SiO}_{2}$ by following the aforementioned method. Next, to enhance the hydrophobicity of the ZIF$8 @ \mathrm{SiO}_{2}$ particles, they modified them with hexadecyltrimethoxysilane.

Incorporation of functional molecules onto the surface of colloidal ZIF-8 crystals has also been explored to construct nanostructured composites. In 2018, Zhu et al. reported the synthesis of colloidal ZIF-8@DPGG and similar colloids (based on other MOFs) via direct coordination of the lipid analog 1,2dipalmitoyl-sn-glycero-3-galloyl (DPGG) onto the external surface of ZIF-8 crystals (Fig. 7, right). ${ }^{55}$ The colloidal stability of the modified DPGG-ZIF-8 particles in nonapolar solvents enabled fabrication of ZIF-8 or ZIF-8/polymer monolayers by evaporation-induced interfacial self-assembly. Moreover, incorporation of a second functional layer onto the DPGGmodified ZIF-8 enabled construction of polyhedral core-shell structures, hybrid lipid-modified-plasmonic vesicles and multicomponent supraparticles.

\section{A special case: ZIF@ZIF crystals}

The bottom-up strategy has also been exploited to obtain new morphologies or complex structures of ZIF@ZIF crystals. Generally, a)
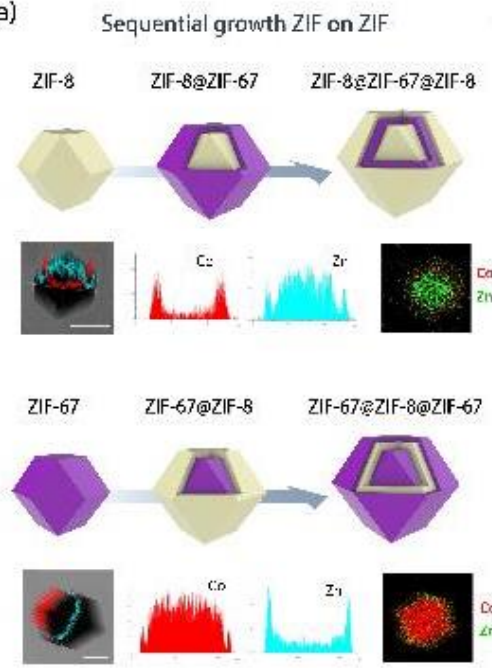

b)

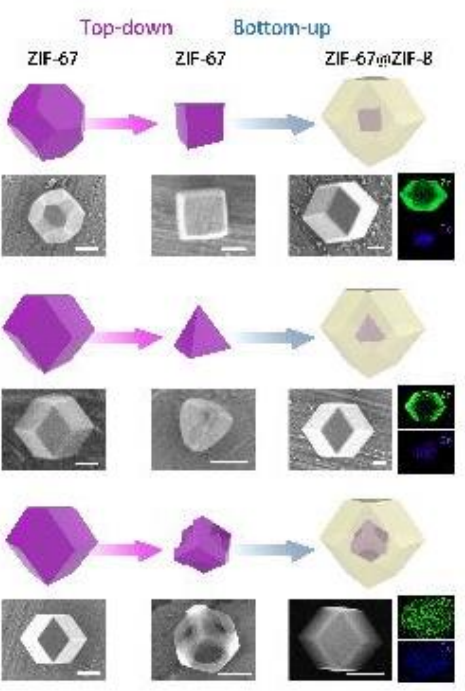

Fig. 8. (a) Schematic illustrating the post-synthetic growth of alternating layers of ZIF-8 or ZIF-67 on top of ZIF-8 (top) or ZIF-67 (bottom), and the corresponding EM images for characterization of the resulting ZIF-on-ZIF hierarchic structures. Scale bar (all micrographs): $100 \mathrm{~nm}{ }^{61} \mathrm{~b}$ ) Schematic of the potential of combining top-down shape modification of ZIF crystals that differ by truncation degree, with subsequent re-growth of the etched structures to yield hierarchic RD ZIF crystals that have cores of different morphologies. of ZIF crystals that differ by truncation degree, with subsequent re-growth of the etched structures to yield hierarchic RD ZIF crystals that have cores of different morphologies.
The corresponding FESEM images and EDX elemental mapping plots (for the hierarchic structures) are shown below each illustration of the ZIF crystals. Scale bars: $200 \mathrm{~nm}$ (top and middle) and $1 \mu \mathrm{m}$ (bottom). . $^{62}$

\begin{tabular}{l} 
Field Code Changed \\
Field Code Changed \\
Field Code Changed \\
Field Code Changed \\
\hline
\end{tabular}

Field Code Changed

Field Code Changed 
pre-synthesized crystals are taken as seeds and subjected to one or more growing steps to yield layered ZIF@ZIF crystals. ${ }^{58-60}$ In 2016, Zhang et al. reported a synthesis of ZIF@ZIF materials in which they controlled the resultant shell thickness (Fig. 8a). First, homogeneous ZIF-8 or ZIF-67 seed crystals were soaked in a methanolic solution of 2-mim and then, a methanolic solution of $\mathrm{Co}(\mathrm{II})$ or $\mathrm{Zn}$ (II), respectively, was added. After stirring for hour, the resultant mixtures were aged for 24 hours at room temperature. The authors systematically studied the effects of the metal/ligand ratio and of the metal source (nitrate or acetate salt) on the shell thickness in ZIF-8 and ZIF-67 particle (size: $90 \mathrm{~nm}$ to $600 \mathrm{~nm}$ ). They found that, at a fixed reaction time and 2-mim concentration, lower concentrations of acetat salt gave ZIF@ZIF particles with the thinnest shells ( $c a .7 \mathrm{~nm}$ ), whereas higher concentrations of nitrate salt yielded the thickest shells (ca. $70 \mathrm{~nm}){ }^{61}$ Their findings were consistent with previously reported results on the nucleation and growth rates of ZIF-8. Later, our group described core-shell ZIF-67@ZIF-8 particles having ZIF-67 cores in cubic, tetrahedral or hollow-box morphologies. ${ }^{62}$ We first obtained the ZIF- 67 cores by selective chemical etching, and then used the etched ZIF- 67 crystals as seeds, optimizing particle growth by varying the $\mathrm{Zn}(\mathrm{II}) / 2-\mathrm{mim}$ concentrations and reaction time for each core morphology (Fig. 8b). Interestingly, all the morphologies - even the hollow box - ended up with the TRD or RD shape to form cubic@TRD, cubic@RD, tetrahedral@TRD, tetrahedral@RD or hollowbox@RD morphologies, as if the etching was reversed. Moreover, we obtained multi-shelled particles by repeating th ZIF growth step. This unique example illustrates the combination of deconstructive and constructive strategies to obtain sophisticated ZIF-based colloidal nanoparticles.

\section{Outlook}

As we have summarized in this review, the past decade has witnessed tremendous advances in the development of colloidal ZIF-8: from the synthesis of highly monodispersed particles with tunable size and shape, to their further use as functional materials and composites. After years of investigation into the respective roles of different reaction parameters in the formation of ZIF-8, the resulting knowledge has led to a veritable toolbox for tailored synthesis of colloidal ZIF-8. Thus, researchers can now prepare complex colloidal ZIF-8 particles that exhibit the dimensions, morphology and homogeneity required for specific purposes, while pushing the limits of crystal engineering to design single-particle composites of ZIF-8 with a diverse array of nanomaterials and biomolecules.

Various recent examples point to the future of the field (Fig. 9), including formation of self-assembled transparent films/monoliths using ultra-small colloidal ZIF-8 particles for use, for example, in shaping monoliths and in optical sensing. 18,63 self-assembly of colloidal ZIF- 8 particles of highly monodisperse size and shape into ordered supercrystals for use in photonics, sensing and other domains: ${ }^{7,15,64}$ formation of functionalized carbons with interesting electrochemical properties using complex colloidal ZIF-8 composites; ${ }^{38,58}$ and design of highly complex single-particle ZIF-8 composites for use in catalysis and biomedicine. ${ }^{62,}$ ENREF $64^{65}$ These are but a

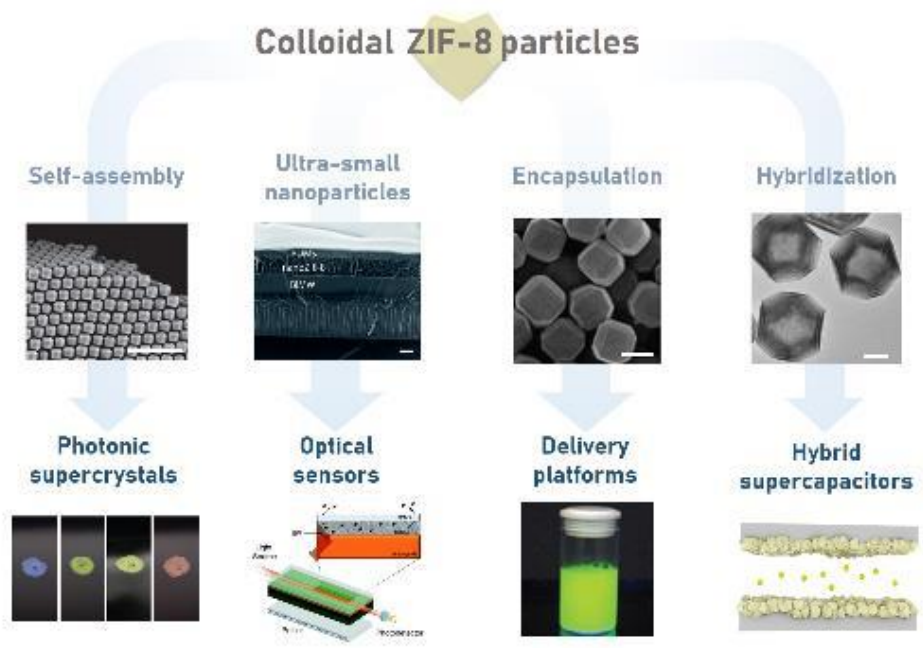

Fig. 9. Diagram of the perspective applications of colloidal ZIF-8 in the different forms discussed in this review. Scale bar (all micrographs): $1 \mu \mathrm{m},{ }^{15,18,39,49}$

Field Code Changed

Field Code Changed

Field Code Changed

Field Code Changed

( should be depicted much bigger.

Changed

Field Code Changed

Field Code Changed

Field Code Changed

Field Code Changed

Field Code Changed

Field Code Changed

Field Code Changed

Field Code Changed 
few examples of how colloidal particles have expanded the properties and applications of ZIF-8. Nonetheless, they exemplify how synthesis of MOFs as homogeneous colloids can confer materials with new properties.

We believe that recent progress in the synthesis and applications of colloidal ZIF-8 has set the stage for furthe development of colloidal MOFs. Indeed, considering the high versatility of MOFs in terms of structure, composition morphology and properties, the possibilities now seem endless. Thus, recently-observed phenomena such as the locomotion of Janus colloidal MOFs could be expanded to MOFs with the required composition, to enable specific applications such as drug delivery or pollutant removal. Alternatively, fabrication of macroscopic materials (e.g. monoliths or membranes) based on close packing of colloidal MOFs for gas sorption and separation applications remains in the very early stages of development. Therefore, expanding the library of available colloidal MOFs that could be used in the fabrication of macroscopic materials will be critical.

We are also confident that MOFs could make key contribution in fundamental colloidal science, by facilitating the discovery of new structures and phenomena. The availability of diverse, highly monodisperse, polyhedral colloidal MOFs of different morphologies should enable the assembly of colloidal crystals with new packing structures. Additionally, the photonic properties of such colloidal crystals could be synergistically combined with specific functions of the colloidal MOFs used in their synthesis, such as luminescence, magnetism, chirality and structural flexibility, to unveil new modular photonic materials with new properties. For example, the concerted expansion/shrinking of flexible MOFs embedded in highlyordered colloidal crystals could give rise to novel inter-particle cooperativity, which we expect would have a significant impact on gas sorption and sensing applications.

\section{Conflicts of interest}

The authors declare no conflict of interest.

\section{Acknowledgements}

This work was supported by the ERC under the EU-FP7 (ERC-CO 615954), and the CERCA Program/Generalitat de Catalunya. ICN2 is supported by the Severo Ochoa program from Spanish MINECO (Grant No. SEV-2017-0706). A.C.S. thanks the Spanish MINECO for Juan de la Cierva fellowship (IJCI-2016-29802).

\section{References}

1 T. Graham, Philos. Trans. Royal Soc., 1861, 151, 183-224.

2 D. Myers, in Surfaces, Interfaces, and Colloids: Principles and Applications, 2nd Ed., Wiley VCH, New York, 1999.

3 M. Pang, A. J. Cairns, Y. Liu, Y. Belmabkhout, H. C. Zeng and M. Eddaoudi, J. Am. Chem. Soc., 2013, 135, 10234-10237.
4 M. Pang, A. J. Cairns, Y. Liu, Y. Belmabkhout, H. C. Zeng and M. Eddaoudi, J. Am. Chem. Soc., 2012, 134, 13176-13179.

5 G. Lu, C. Cui, W. Zhang, Y. Liu and F. Huo, Chem. Asian J., 2013 8. Lu, C. C2.

6 M. Sindoro, A.-Y. Jee and S. Granick, Chem. Commun., 2013, 49, 9576-9578.

M. Sindoro, N. Yanai, A.-Y. Jee and S. Granick, Acc. Chem. Res. 2014, 47, 459-469.

8 X.-C. Huang, Y.-Y. Lin, J.-P. Zhang and X.-M. Chen, Angew. Chem. Int. Ed., 2006, 45, 1557-1559.

9 K. S. Park, Z. Ni, A. P. Côté, J. Y. Choi, R. Huang, F. J. UribeRomo, H. K. Chae, M. O'Keeffe and O. M. Yaghi, Proc. Natl. Acad. Sci. U.S.A, 2006, 103, 10186-10191.

10 J. Cravillon, S. Münzer, S.-J. Lohmeier, A. Feldhoff, K. Huber and M. Wiebcke, Chem. Mater., 2009, 21, 1410-1412.

11 A. Schejn, L. Balan, V. Falk, L. Aranda, G. Medjahdi and R. Schneider, CrystEngComm, 2014, 16, 4493-4500.

12 Y. Zhang, Y. Jia, M. Li and L. a. Hou, Sci. Rep., 2018, 8, 9597.

13 H. H.-M. Yeung, A. F. Sapnik, F. Massingberd-Mundy, M. W. Gaultois, Y. Wu, D. A. X. Fraser, S. Henke, R. Pallach, N. Heidenreich, O. V. Magdysyuk, N. T. Vo and A. L. Goodwin Angew. Chem. Int. Ed., 2019, 58, 566-571.

14 J. Cravillon, R. Nayuk, S. Springer, A. Feldhoff, K. Huber and M. Wiebcke, Chem. Mater., 2011, 23, 2130-2141.

15 C. Avci, I. Imaz, A. Carné-Sánchez, J. A. Pariente, N. Tasios, J. Pérez-Carvajal, M. I. Alonso, A. Blanco, M. Dijkstra, C. Lópe and D. Maspoch, Nat. Chem., 2017, 10, 78

16 E. M. Mahdi and J.-C. Tan, Polymer, 2016, 97, 31-43.

17 S. R. Venna, J. B. Jasinski and M. A. Carreon, J. Am. Chem. Soc. 2010, 132, 18030-18033.

18 B. Chocarro-Ruiz, J. Pérez-Carvajal, C. Avci, O. Calvo-Lozano, M. I. Alonso, D. Maspoch and L. M. Lechuga, J. Mater. Chem. A, 2018, 6, 13171-13177.

19 S. Hermes, T. Witte, T. Hikov, D. Zacher, S. Bahnmüller, G. Langstein, K. Huber and R. A. Fischer, J. Am. Chem. Soc., 2007 129, 5324-5325.

20 T. Tsuruoka, S. Furukawa, Y. Takashima, K. Yoshida, S. Isoda and S. Kitagawa, Angew. Chem. Int. Ed., 2009, 48, 4739-4743.

21 N. Yanai, M. Sindoro, J. Yan and S. Granick, J. Am. Chem. Soc., 2013, 135, 34-37

22 K. Kida, M. Okita, K. Fujita, S. Tanaka and Y. Miyake, CrystEngComm, 2013, 15, 1794-1801.

23 J. Cravillon, C. A. Schröder, H. Bux, A. Rothkirch, J. Caro and M. Wiebcke, CrystEngComm, 2012, 14, 492-498.

24 X. Xu, Y. Sun, Q. Zhang, S. Wang, L. Zhang, Z. Wu and G. Lu, ChemistrySelect, 2016, 1, 1763-1767.

25 G. Zhan and H. C. Zeng, Nat. Commun., 2018, 9, 3778.

26 C. Avci, J. Ariñez-Soriano, A. Carné-Sánchez, V. Guillerm, C. Carbonell, I. Imaz and D. Maspoch, Angew. Chem. Int. Ed., 2015, 127, 14625-14629.

27 W. Niu, S. Zheng, D. Wang, X. Liu, H. Li, S. Han, J. Chen, Z. Tang and G. Xu, J. Am. Chem. Soc., 2009, 131, 697-703.

28 Y. Pan, D. Heryadi, F. Zhou, L. Zhao, G. Lestari, H. Su and Z. Lai, CrystEngComm, 2011, 13, 6937-6940.

29 S. Tanaka, K. Fujita, Y. Miyake, M. Miyamoto, Y. Hasegawa, T. Makino, S. Van der Perre, J. Cousin Saint Remi, T. Van Assche, G. V. Baron and J. F. M. Denayer, J. Phys. Chem. C, 2015, 119, 28430-28439.

30 F. Yang, H. Mu, C. Wang, L. Xiang, K. X. Yao, L. Liu, Y. Yang, Y. Han, Y. Li and Y. Pan, Chem. Mater., 2018, 30, 3467-3473.

31 G. Zheng, Z. Chen, K. Sentosun, I. Pérez-Juste, S. Bals, L. M. LizMarzán, I. Pastoriza-Santos, J. Pérez-Juste and M. Hong, Nanoscale, 2017, 9, 16645-16651.

32 S. Jeoung, I. T. Ju, J. H. Kim, S. H. Joo and H. R. Moon, J. Mater Chem. A, 2018, 6, 18906-18911.

$33 \mathrm{M}$. Hu, Y. Ju, K. Liang, T. Suma, J. Cui and F. Caruso, Adv. Funct. Mater., 2016, 26, 5827-5834. 
34 K. Shen, L. Zhang, X. Chen, L. Liu, D. Zhang, Y. Han, J. Chen, J. Long, R. Luque, Y. Li and B. Chen, Science, 2018, 359, 206-210. 35 H. Chen, K. Shen, J. Chen, X. Chen and Y. Li, J. Mater. Chem. A 2017, 5, 9937-9945.

36 H. J. Lee, W. Cho and M. Oh, Chem. Commun., 2012, 48, 221 223.

37 L.-Y. Chou, P. Hu, J. Zhuang, J. V. Morabito, K. C. Ng, Y.-C. Kao, S.-C. Wang, F.-K. Shieh, C.-H. Kuo and C.-K. Tsung, Nanoscale, 2015, 7, 19408-19412.

38 P. Zhang, B. Y. Guan, L. Yu and X. W. Lou, Angew. Chem. Int Ed., 2017, 56, 7141-7145.

39 P. Zhang, B. Y. Guan, L. Yu and X. W. Lou, Chem, 2018, 4, 162173.

40 J. Yang, F. Zhang, H. Lu, X. Hong, H. Jiang, Y. Wu and Y. Li, Angew. Chem. Int. Ed., 2015, 54, 10889-10893.

41 G. Lu, S. Li, Z. Guo, O. K. Farha, B. G. Hauser, X. Qi, Y. Wang, X. Wang, S. Han, X. Liu, J. S. DuChene, H. Zhang, Q. Zhang, X. Chen, J. Ma, S. C. J. Loo, W. D. Wei, Y. Yang, J. T. Hupp and F. Huo, Nat. Chem., 2012, 4, 310.

42 G. Zheng, S. de Marchi, V. López-Puente, K. Sentosun, L. Polavarapu, I. Pérez-Juste, E. H. Hill, S. Bals, L. M. Liz-Marzán, I. Pastoriza-Santos and J. Pérez-Juste, Small, 2016, 12, 39353943.

43 P. Wang, J. Zhao, X. Li, Y. Yang, Q. Yang and C. Li, Chem. Commun., 2013, 49, 3330-3332.

44 N. Liédana, A. Galve, C. Rubio, C. Téllez and J. Coronas, ACS Appl. Mater. Interfaces, 2012, 4, 5016-5021.

45 J. Zhuang, C.-H. Kuo, L.-Y. Chou, D.-Y. Liu, E. Weerapana and C.-K. Tsung, ACS Nano, 2014, 8, 2812-2819.

46 H. Zheng, Y. Zhang, L. Liu, W. Wan, P. Guo, A. M. Nyström and X. Zou, J. Am. Chem. Soc., 2016, 138, 962-968.

47 F. Lyu, Y. Zhang, R. N. Zare, J. Ge and Z. Liu, Nano Lett., 2014 14, 5761-5765.

48 X. Wu, J. Ge, C. Yang, M. Hou and Z. Liu, Chem. Commun. 2015, 51, 13408-13411.

49 K. Liang, R. Ricco, C. M. Doherty, M. J. Styles, S. Bell, N. Kirby, S. Mudie, D. Haylock, A. J. Hill, C. J. Doonan and P. Falcaro, Nat. Comm., 2015, 6, 7240.

50 E. Astria, M. Thonhofer, R. Ricco, W. Liang, A. Chemelli, A. Tarzia, K. Alt, C. E. Hagemeyer, J. Rattenberger, H. Schroettner, T. Wrodnigg, H. Amenitsch, D. M. Huang, C. J. Schroettner, T. Wrodnigg, H. Amenitsch, D. M. Huang, C. J.

51 Y. Feng, H. Wang, S. Zhang, Y. Zhao, J. Gao, Y. Zheng, P. Zhao, Z. Zhang, M. J. Zaworotko, P. Cheng, S. Ma and Y. Chen, Adv. Mater., 2019, 31, 1805148

52 Z. Li and H. C. Zeng, Chem. Mater., 2013, 25, 1761-1768.

53 L. He, L. Li, T. Wang, H. Gao, G. Li, X. Wu, Z. Su and C. Wang, Dalton Trans., 2014, 43, 16981-16985.

54 A. Ayala, C. Carbonell, I. Imaz and D. Maspoch, Chem Commun., 2016, 52, 5096-5099.

55 W. Zhu, G. Xiang, J. Shang, J. Guo, B. Motevalli, P. Durfee, J. O. Agola, E. N. Coker and C. J. Brinker, Adv. Funct. Mater., 2018 28, 1705274.

56 L. He, L. Li, L. Zhang, S. Xing, T. Wang, G. Li, X. Wu, Z. Su and C. Wang, CrystEngComm, 2014, 16, 6534-6537.

57 C. Wu, Q. Liu, R. Chen, J. Liu, H. Zhang, R. Li, K. Takahashi, P. Liu and J. Wang, ACS Appl. Mater. Interfaces, 2017, 9, $11106-$ 11115.

58 J. Tang, R. R. Salunkhe, J. Liu, N. L. Torad, M. Imura, S. Furukawa and Y. Yamauchi, J. Am. Chem. Soc., 2015, 137, 1572-1580.

59 C. Rösler, A. Aijaz, S. Turner, M. Filippousi, A. Shahabi, W. Xia, G. Van Tendeloo, M. Muhler and R. A. Fischer, Chem. Eur. J 2016, 22, 3304-3311

60 J. Yang, F. Zhang, H. Lu, X. Hong, H. Jiang, Y. Wu and Y. Li, Angew. Chem. Int. Ed., 2015, 127, 11039-11043.

61 J. Zhang, T. Zhang, K. Xiao, S. Cheng, G. Qian, Y. Wang and Y. Feng, Cryst. Growth Des., 2016, 16, 6494-6498.
62 C. Avci, A. Yazdi, M. Tarrés, E. Bernoud, N. G. Bastús, V. Puntes, I. Imaz, X. Ribas and D. Maspoch, ACS Appl. Mater. Interfaces, 2018, 10, 23952-23960.

63 T. Tian, J. Velazquez-Garcia, T. D. Bennett and D. FairenJimenez, J. Mater. Chem. A, 2015, 3, 2999-3005.

64 L. Bai, Y. He, J. Zhou, Y. Lim, V. C. Mai, Y. Chen, S. Hou, Y. Zhao, J. Zhang and H. Duan, Adv. Opt. Mater., 0, 1900522.

65 M. Hoop, C. F. Walde, R. Riccò, F. Mushtaq, A. Terzopoulou, X.-Z. Chen, A. J. deMello, C. J. Doonan, P. Falcaro, B. J. Nelson, J. Puigmartí-Luis and S. Pané, Appl. Mater. Today., 2018, 11, $13-21$ 